\title{
REVIEWS.
}

\section{FRACTURE AND OTHER BONE AND JOINT INJURIES.}

By R. Watson-Jones. Pp. 723. E. \& S. Livingstone, Edinburgh. 1940. Price 50s. Od.

This is undoubtedly the best book on the subject that has so far appeared. Mr. Watson-Jones is a true disciple of the Liverpool School of Orthopædics, founded by Hugh Owen Thomas and fathered by Robert Jones. Mr. Watson-Jones throughout this volume displays all the characteristic thoroughness, the singleness of purpose and the lucidity of expression of his predecessors.

The field of surgery that is covered by the title of this book is so wide, and there is so much useful information to impart, that little space has been devoted to the various aspects of controversial questions, whether of pathology or technique. Mr. Watson-Jones always has a very clear cut opinion and when he has expressed it, the reader is left in no doubt as to what he thinks, e.g. p. 13: "There is only one cause of nonunion (of fractures) and that is failure of adequate immobilisation."

In a book where all is good it is difficult to pick out any part for special mention in a short review. Possibly the reader may be tempted first to turn to the chapter on fractures of the dorso-lumbar vertebræ, to read again the description of Mr. Watson-Jones's well-known method of reducing and immobilising these fractures. This chapter may be taken as typical of others in the book. There is given an exhaustive analysis of the mechanics of the injury, first the common flexion fracture and then the rare extension fractures. The author does not concern himself with such trans-atlantic modifications as "saucerisation." This to him is just a variety of crush fracture not worthy of special mention; its pathology is the same, its treatment is the same and its prognosis is the same.

Diagrams precede X-ray films so that there shall be no difficulty in understanding the latter. Perhaps one could have wished that a little more space had been devoted to the differential diagnosis of early and late fractures of the vertebræ which has become a medico-legal issue of considerable importance. The principles of reduction of the fractured vertebra by hyper-extension and the actual practical method of reduction and application of plaster are made doubly clear by serial photographs, not only of the correct method but also of the common errors into which the inexperienced surgeon may fall. The section finishes with a description of the exercises which must be practised whilst the plaster is still being worn.

Nothing will strike the reader more forcibly than Mr. Watson-Jones's abhorrence of passive movement: "Massage and movements commonly prescribed as a treatment for stiff joints is one of the commonest causes of stiff joints. When the adhesions already formed around the joints are violently stretched or torn, there is reactionary exudation which produces fresh adhesions. If this treatment is repeated day after day, the traumatic exudation recurs. And although every day some adhesions are stretched, many more develop. Such treatment delays the recovery of movement in every joint and in the more susceptible joints of the upper limb, the finger, elbow and shoulder joints, measurements show that movement steadily decreases so long as the treatment continues .. . The only way to convert slight temporary stiffness of a finger into permanent irrecoverable stiffness is to stretch the joint." Active exercise is the only successful method of restoring movement to stiff joints.

It is a pity that except in the case of a few special fractures, space has not permitted the author to deal more fully with the nature of the exercises which he recommends. Presumably few of the exercises are practised under supervision at the hospital, as the gymnasium accommodation in the plan of the Liverpool Royal Infirmary fracture department (figure 1035) is relatively small.

The illustrations, whether reproductions of diagrams, drawings, photographs or X-ray films, are all exceptionally good. Paper, printing and indexing are of the same high standard and reflect the greatest credit on the publishers and although the subject matter and general presentation of this book has forced the reviewer to study it page by page and detail by detail, he has been denied the smug satisfaction of finding a mistake in someone else's work.

In " Fractures," Mr. Watson-Jones has worthily upheld the Owen-Thomas - Robert Jones tradition.

\section{ILLUSTRATIONS OF SURGICAL TREATMENT INSTRUMENTS \& APPLIANCES.}

By ERIC L. FarquHaRSON, M.D., F.R.C.S.E. Foreword by SIR JoHN Frazer, M.C., M.D., Ch.M., F.R.C.S.E. E. \& S. Livingstone, Edinburgh. 1939. Price 20s. Od.

This is a thoroughly practical work and can be recommended to all surgeons, whether they be senior or junior. The methods described are the author's own, the descriptions are lucid, the illustrations ample and good, and there is little in the methods themselves which calls for any criticism. We have rarely read such clear and concise descriptions of technical procedure.

The author starts with intravenous and blood transfusions. We should have liked a little more emphasis laid on the dangers of rigors, which seem to be due to impurities in the distilled water rather than to impurities in the sodium chloride as suggested by the author. Also, we are a little surprised that the method of using stored blood is not mentioned.

The rest of the work consists chiefly of the treatment of fractures, followed by a chapter on deformities. A third of the work is taken up with illustrations of instruments and appliances. We doubt if this is really worth while; it becomes more or less of an instrument maker's catalogue, 